\title{
Quantitative assessment of changes in surface particulate matter concentrations over China during the COVID-19 pandemic and their implications for Chinese economic activity
}

5 Hyun Cheol Kim ${ }^{1,2, *}$, Soontae Kim ${ }^{3}$, Mark Cohen ${ }^{1}$, Changhan Bae ${ }^{4}$, Dasom Lee ${ }^{5}$, Rick Saylor ${ }^{1}$, Minah $\mathrm{Bae}^{3}$, Eunhye Kim ${ }^{3}$, Byeong-Uk Kim ${ }^{6}$, Jin-Ho Yoon ${ }^{5}$, and Ariel Stein ${ }^{1}$

\footnotetext{
${ }^{1}$ Air Resources Laboratory, National Oceanic and Atmospheric Administration, College Park, MD, USA

${ }^{2}$ Cooperative Institute for Satellite Earth System Studies, University of Maryland, College Park, MD, USA

$10{ }^{3}$ Department of Environmental and Safety Engineering, Ajou University, Suwon, South Korea

${ }^{4}$ National Air Emission Inventory and Research Center, Sejong, South Korea

${ }^{5}$ School of Earth Sciences and Environmental Engineering, Gwangju Institute of Science and Technology, Gwangju, South Korea

${ }^{6}$ Georgia Environmental Protection Division, Atlanta, GA, USA
}

15 Correspondence to: Hyun Cheol Kim (hyun.kim@,noaa.gov) 
20 Table S1 Responses of surface $\mathbf{P M}_{2.5}$ concentration for emission reduction sensitivity tests. Baseline model was simulated using CMAQ with CREATE emission inventory for 2016. Changes of surface PM2.5 concentrations (and percentages) from the baseline simulation are shown for 1) all emission 50\% reduction, 2) SOx and NOx emission 35\% reduction, 3) NOx emission 35\% reduction, 4) SOx emission $35 \%$ reduction, and 5 ) $\mathrm{NH}_{3}$ emission $35 \%$ reduction. BTH denotes for Beijing-Tianjin-Hebei region, and YRD\&SD denotes Yangtze River Delta and Shandong region.

\begin{tabular}{ccccccc}
\hline & Base & All Emission & SOx\&NOx & NOx & SOx & NH3 \\
& Model & $-50 \%$ & $-35 \%$ & $-35 \%$ & $-35 \%$ & $-35 \%$ \\
\hline \multirow{2}{*}{ China } & $36.9 \mu \mathrm{g} / \mathrm{m}^{3}$ & $-18.9 \mu \mathrm{g} / \mathrm{m}^{3}$ & $-4.1 \mu \mathrm{g} / \mathrm{m}^{3}$ & $-2.9 \mu \mathrm{g} / \mathrm{m}^{3}$ & $-1.2 \mu \mathrm{g} / \mathrm{m}^{3}$ & $-3.3 \mu \mathrm{g} / \mathrm{m}^{3}$ \\
& & $(-51 \%)$ & $(-11 \%)$ & $(-8 \%)$ & $(-3 \%)$ & $(-9 \%)$ \\
\hline \multirow{2}{*}{ BTH } & $53.4 \mu \mathrm{g} / \mathrm{m}^{3}$ & $-26.8 \mu \mathrm{g} / \mathrm{m}^{3}$ & $-3.7 \mu \mathrm{g} / \mathrm{m}^{3}$ & $-2.2 \mu \mathrm{g} / \mathrm{m}^{3}$ & $-1.5 \mu \mathrm{g} / \mathrm{m}^{3}$ & $-4.1 \mu \mathrm{g} / \mathrm{m}^{3}$ \\
& & $(-50 \%)$ & $(-7 \%)$ & $(-4 \%)$ & $(-3 \%)$ & $(-8 \%)$ \\
\hline YRD\&SD & $41.3 \mu \mathrm{g} / \mathrm{m}^{3}$ & $-21.2 \mu \mathrm{g} / \mathrm{m}^{3}$ & $-4.4 \mu \mathrm{g} / \mathrm{m}^{3}$ & $-3.1 \mu \mathrm{g} / \mathrm{m}^{3}$ & $-1.3 \mu \mathrm{g} / \mathrm{m}^{3}$ & $-4.2 \mu \mathrm{g} / \mathrm{m}^{3}$ \\
& & $(-51 \%)$ & $(-11 \%)$ & $(-8 \%)$ & $(-3 \%)$ & $(-10 \%)$ \\
\hline
\end{tabular}




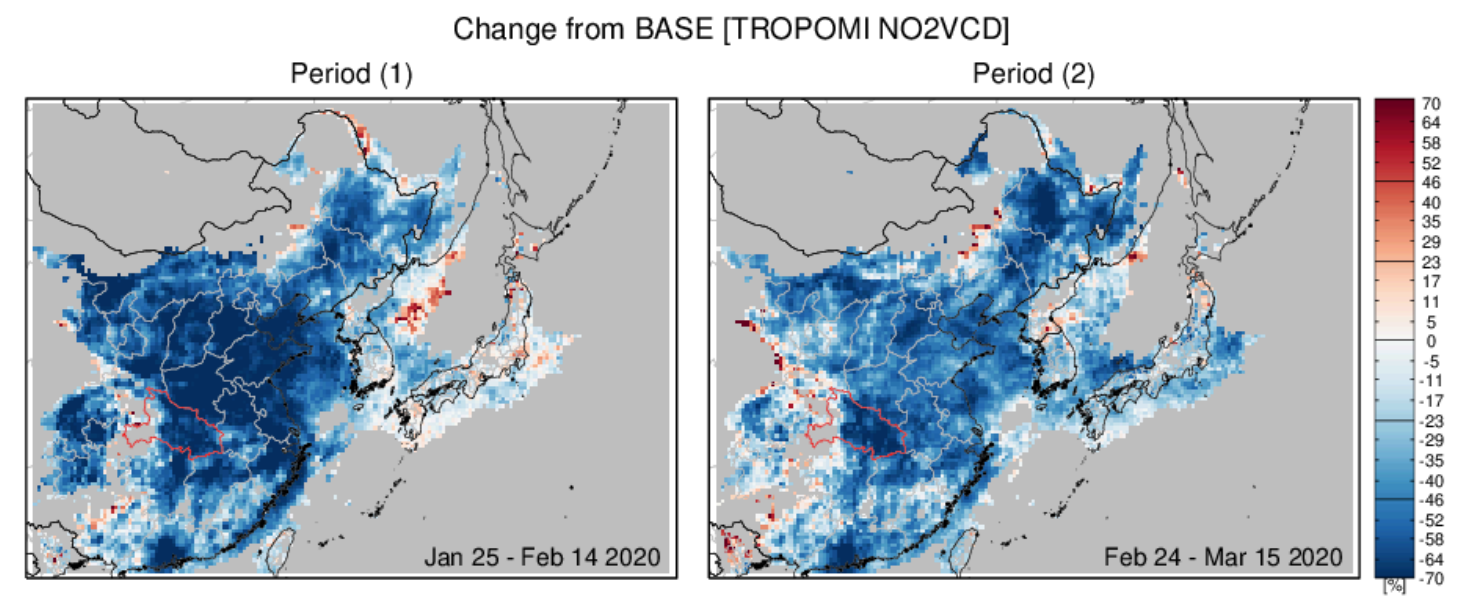

Figure S1 Spatial distribution of the change in TROPOMI NO2 vertical column densities from the base period (Figure 1) during the 30 maximum impact period (January 25 - February 14, 2020) and the recovery period (February 24 - March 15, 2020). Hubei province is marked in red. Areas with NO2 column density less than 1x1015 mole/cm2 in the base period were marked in gray. 
Model Performance Evaluation 2017 - 2020
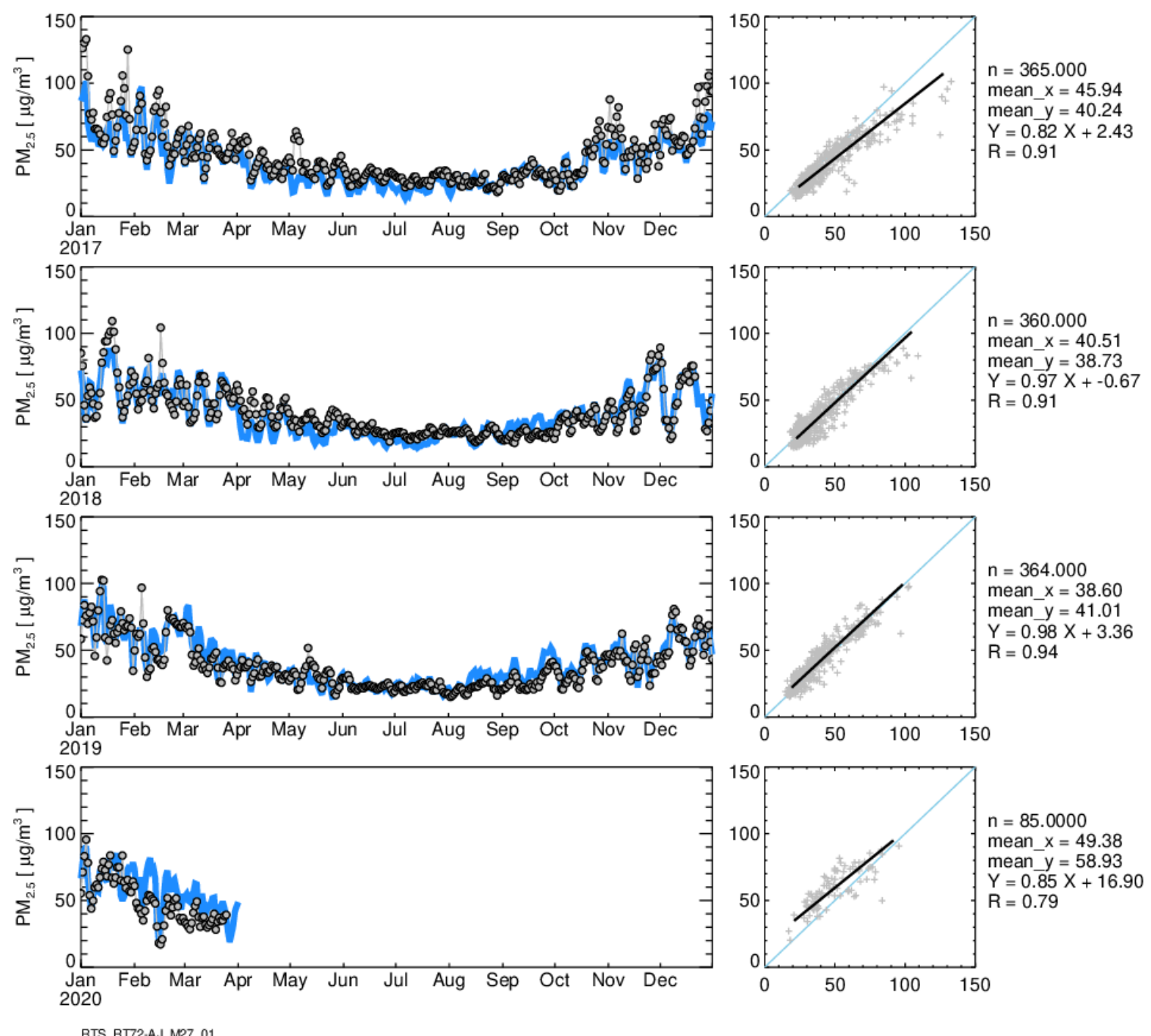

35 Figure S2 Time series comparisons of model and surface observations for $\mathrm{PM}_{2.5}, \mathrm{NO}_{2}$, and $\mathrm{SO}_{2}$. 
Model Performance Evaluation 2017 - 2020
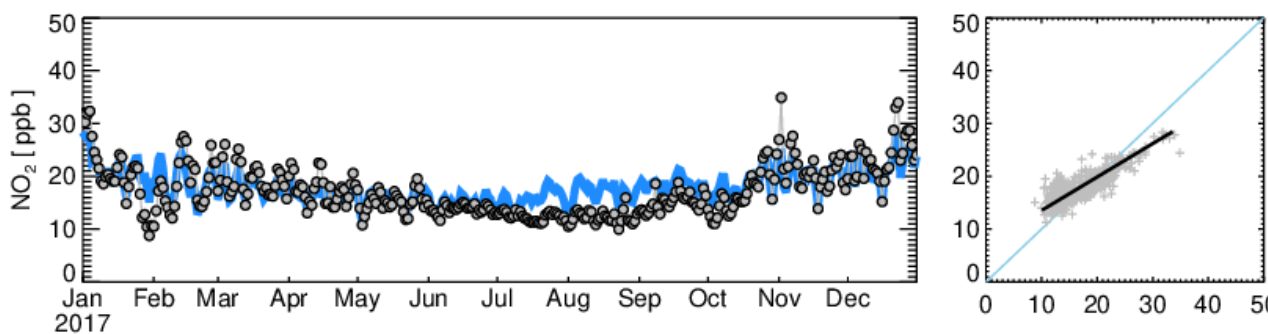

$\mathrm{n}=365.000$

mean_x $=17.21$

mean $y=18.10$

$\mathrm{Y}=0.63 \mathrm{X}+7.22$

$R=0.83$
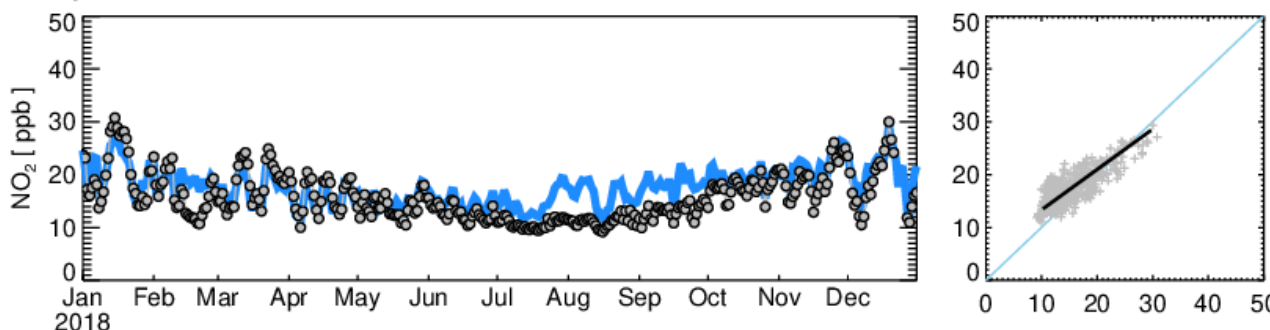

$\mathrm{n}=360.000$

mean_x $=15.68$

mean $y=17.67$

$\mathrm{Y}=0.76 \mathrm{X}+5.70$

$\mathrm{R}=0.81$
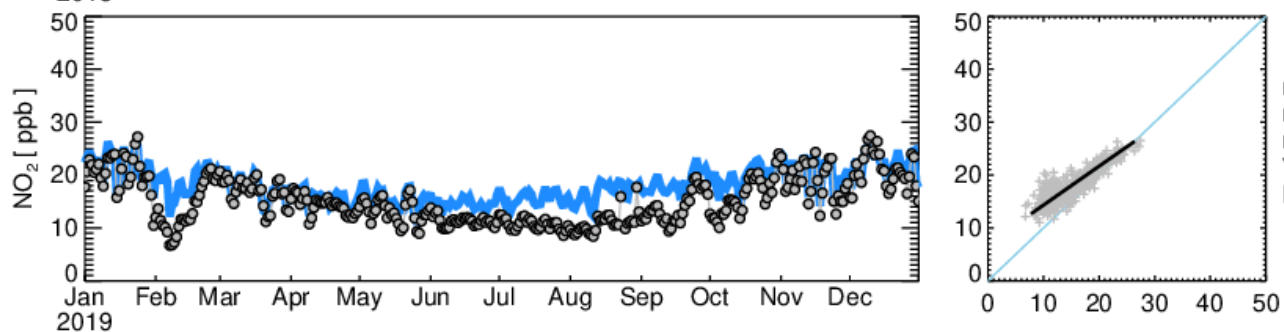

$\mathrm{n}=364.000$

mean $x=15.11$

mean_ $y=18.06$

$\mathrm{Y}=0.74 \mathrm{X}+6.95$

$R=0.87$
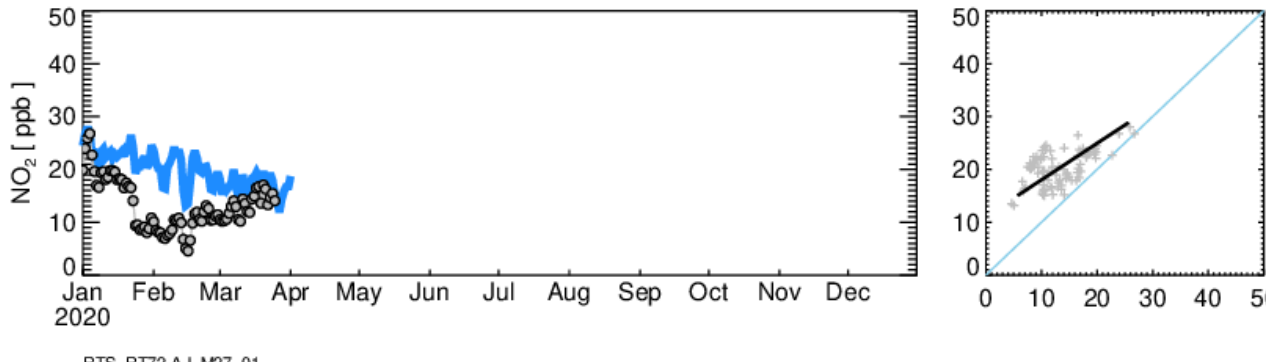

$\mathrm{n}=85.0000$

mean_x $=13.18$

mean $y=20.23$

$Y=0.69 X+11.11$

$\mathrm{R}=0.57$

Figure S2. Continued 
Model Performance Evaluation 2017 - 2020
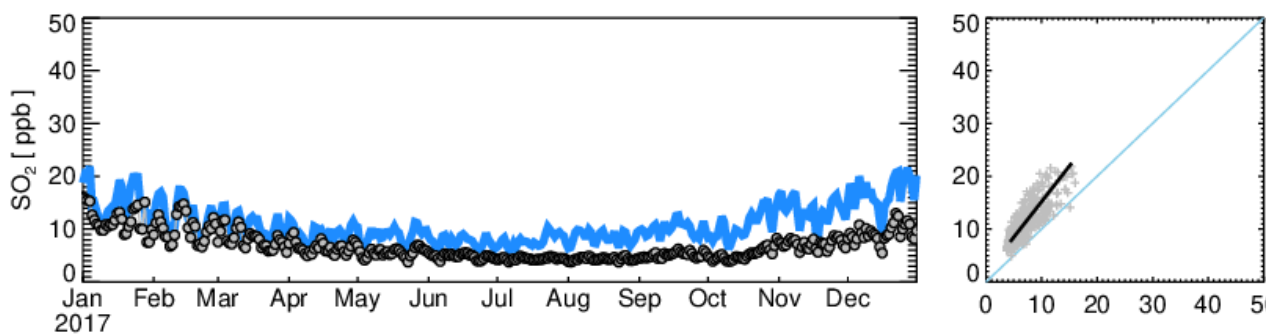

$\mathrm{n}=365.000$ mean_x $=6.88$ mean $y=10.99$

$Y=1.35 X+1.73$

$R=0.83$
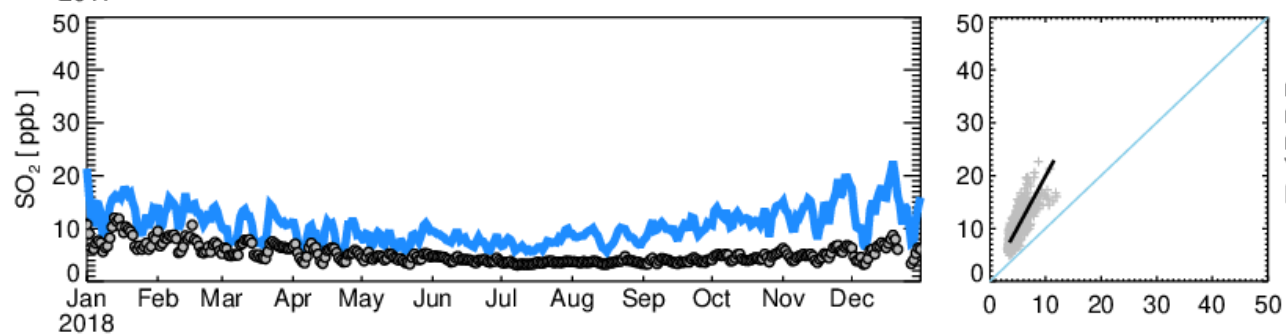

$\mathrm{n}=360.000$ mean_x $=5.15$

mean $y=10.49$

$\mathrm{Y}=1.94 \mathrm{X}+0.50$

$\mathrm{R}=0.75$
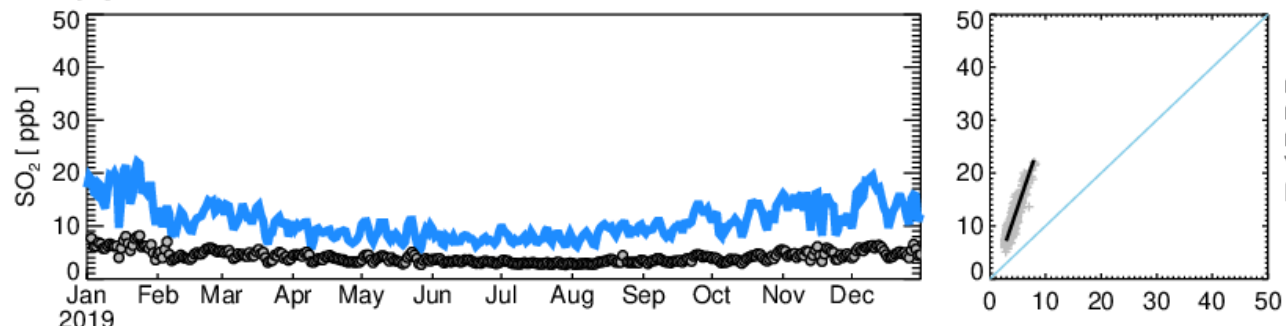

$\mathrm{n}=364.000$

mean $x=4.15$

mean_ $y=10.95$

$Y=3.06 X+-1.76$

$R=0.92$
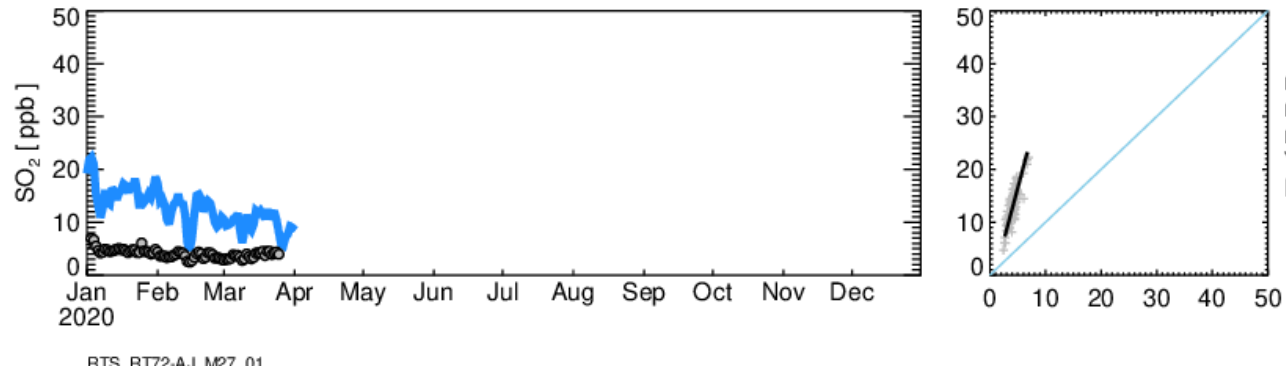

$\mathrm{n}=85.0000$ mean_ $x=4.11$

mean $y=12.97$

$\mathrm{Y}=3.94 \mathrm{X}+-3.23$

RTS_RT72-AJ_M27_01

Figure S2. Continued. 

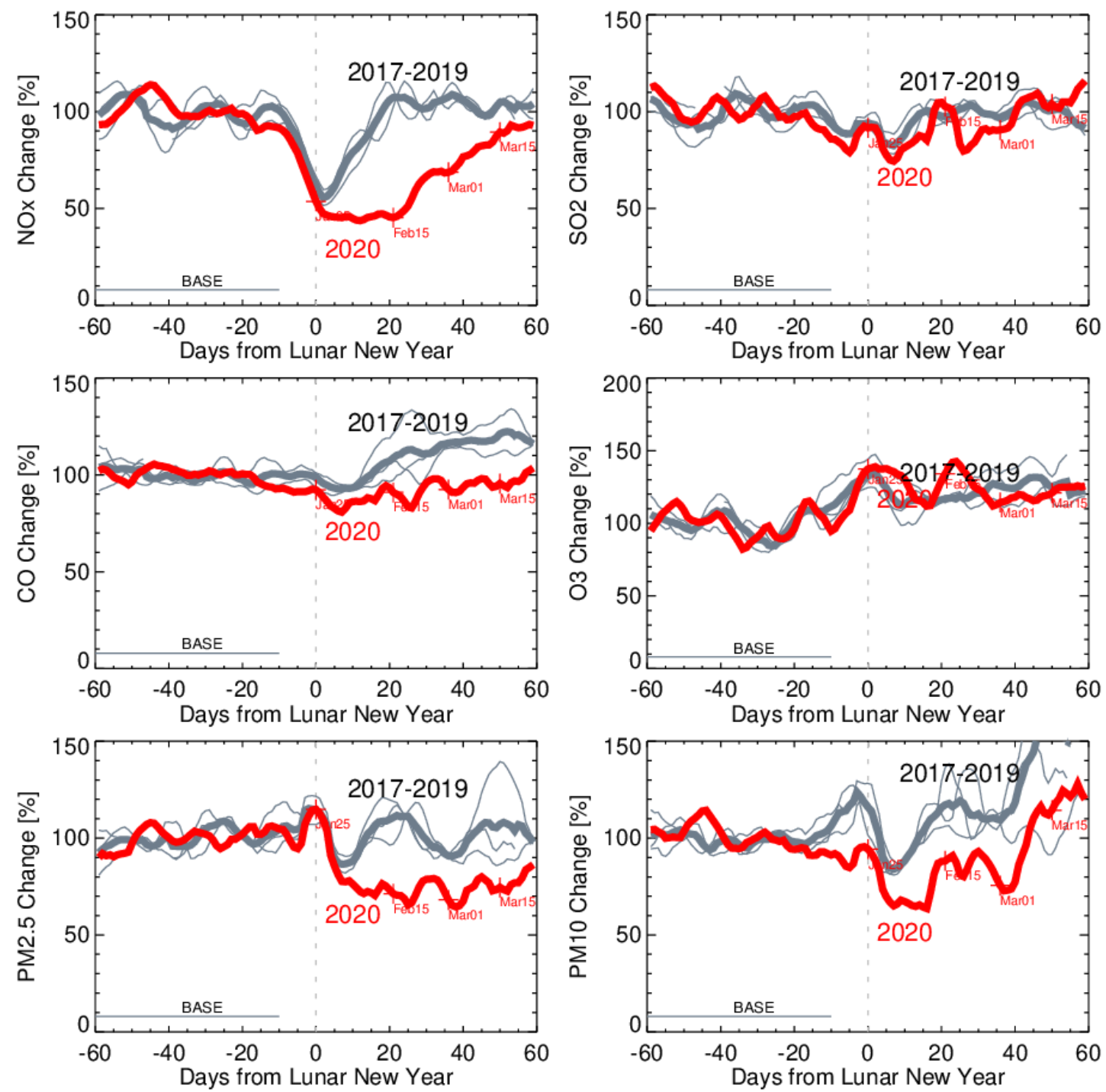

Figure S3 Time series of estimated emissions changes for NO2, SO2, CO, O3, PM2.5, and PM10 using surface monitors across China.

(hray lines indicate 2017-2019 variations with their average in the thick gray line, whereas the red line indicates the 2020 variation. BASE is used as the pre-LNY period, and time series was calculated as relative changes from the average of the base period. 

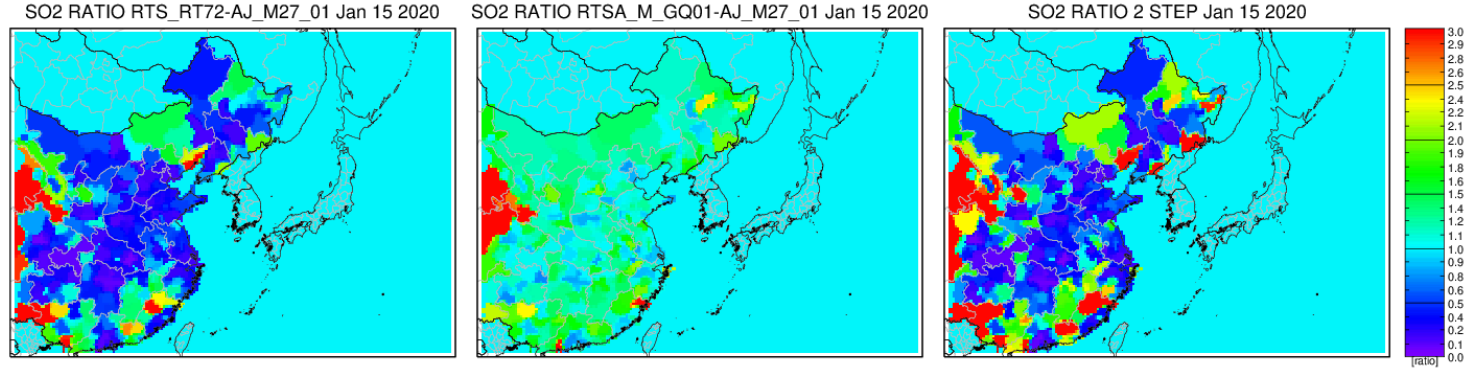

Figure S4 Spatial distribution of SO2 emission adjustment factors for 1-step adjustment (left), and $\beta$ values (middle), and 2-step 50 adjustment factors (right). 

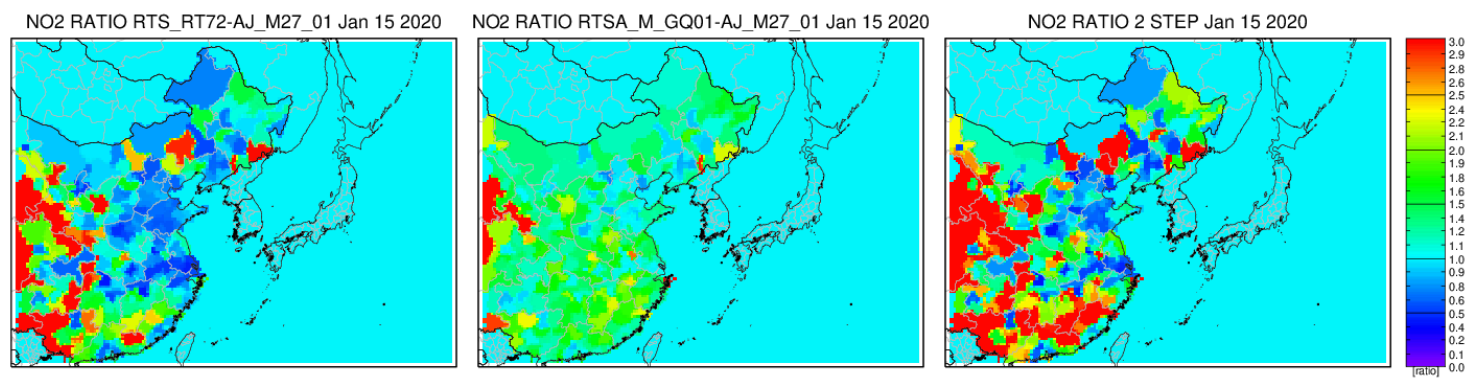

55 Figure S5 Spatial distribution of NO2 emission adjustment factors for 1-step adjustment (left), and $\beta$ values (middle), and 2-step adjustment factors (right). 

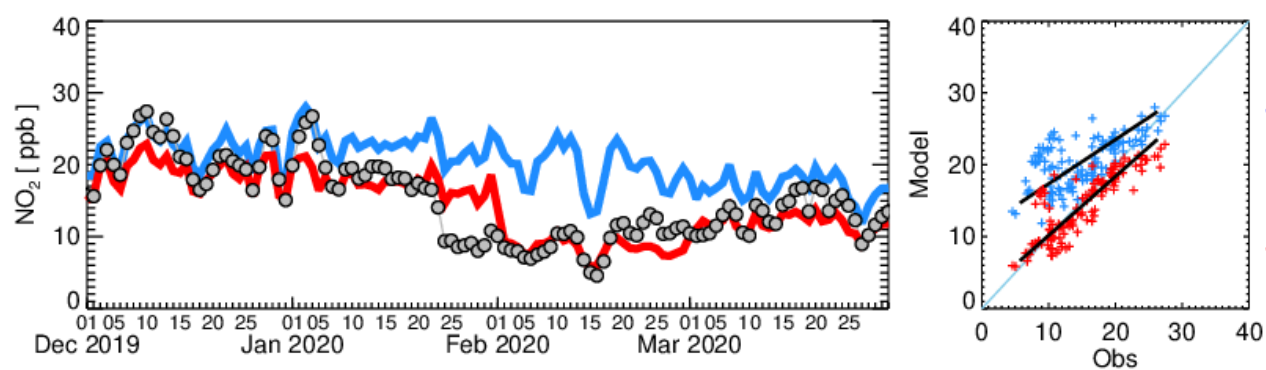

$n=122.000$

mean_x $=15.05$

mean $y=20.47$

$\mathrm{Y}=0.62 \mathrm{X}+11.19$

$\mathrm{R}=0.65$

$n=122.000$

mean $x=15.05$

mean $y=14.31$

$Y=0.82 X+1.95$
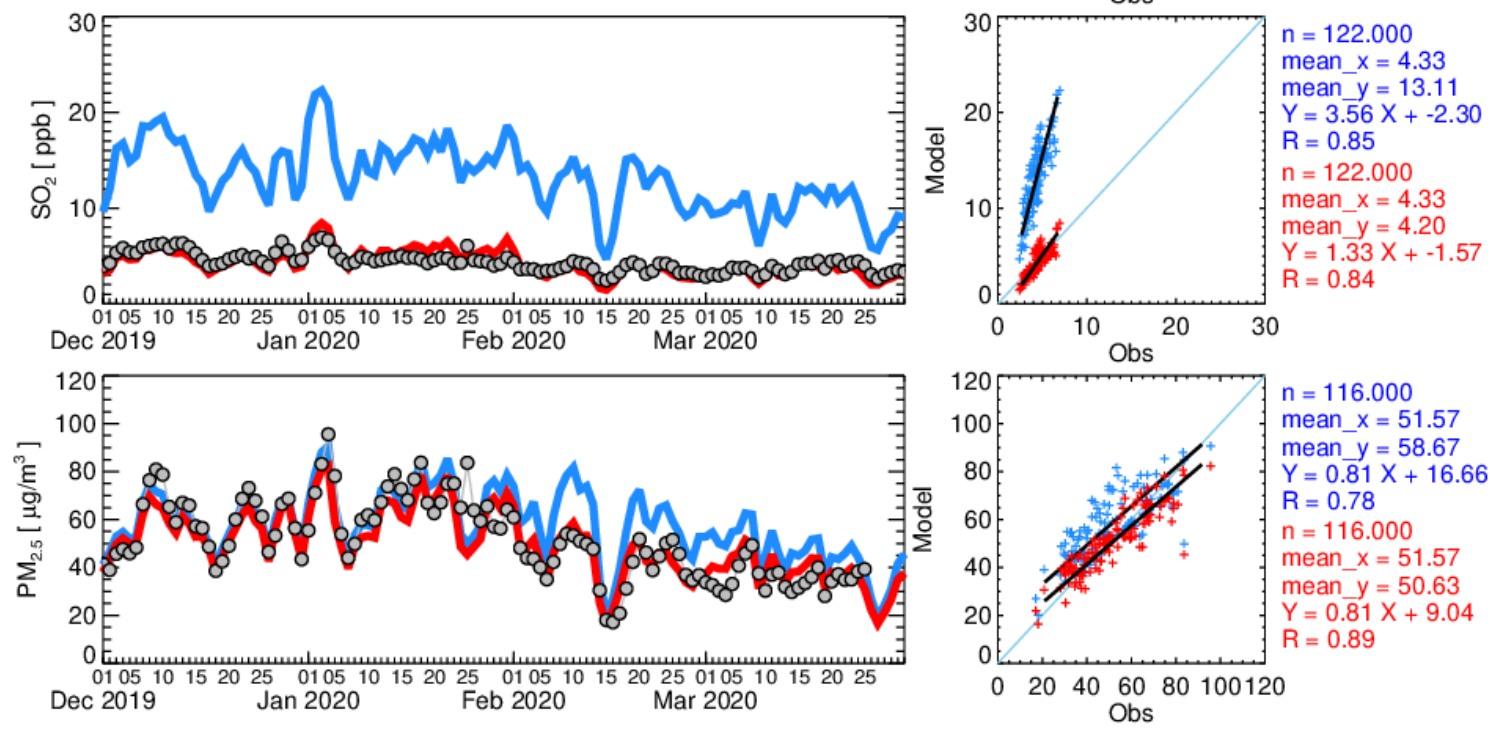

60 Figure S6 Time series of surface concentrations of NO2, SO2 and PM2.5 for the baseline simulation (blue) and adjusted-emission simulations (red). Monthly emission adjustment factors were used with a fixed emission-to-concentration conversion factor (i.e. $\beta=1$ ). 
(A)

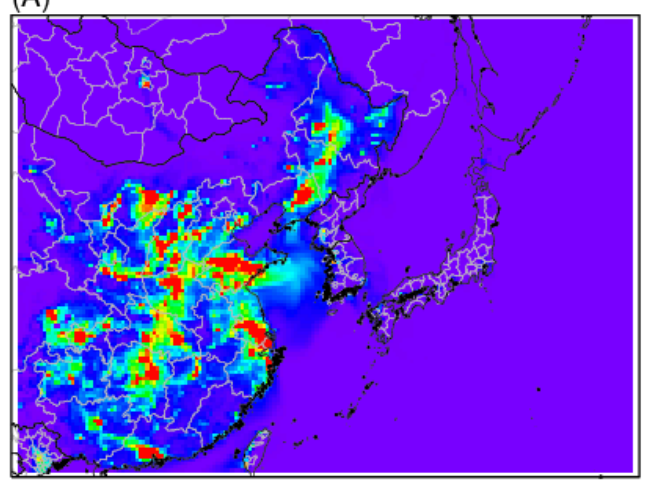

(C)

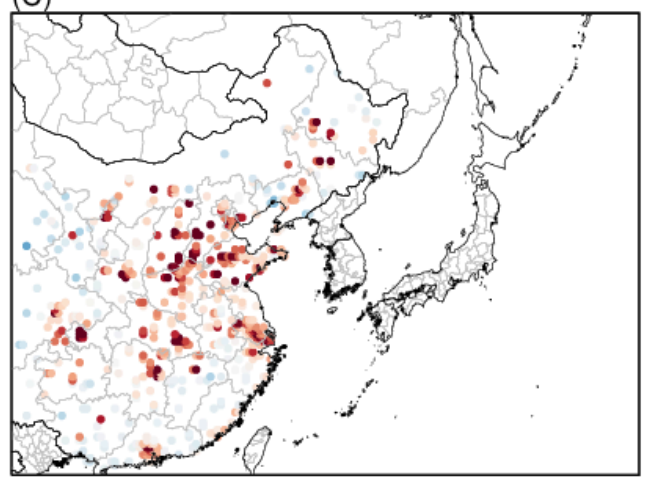

(E)

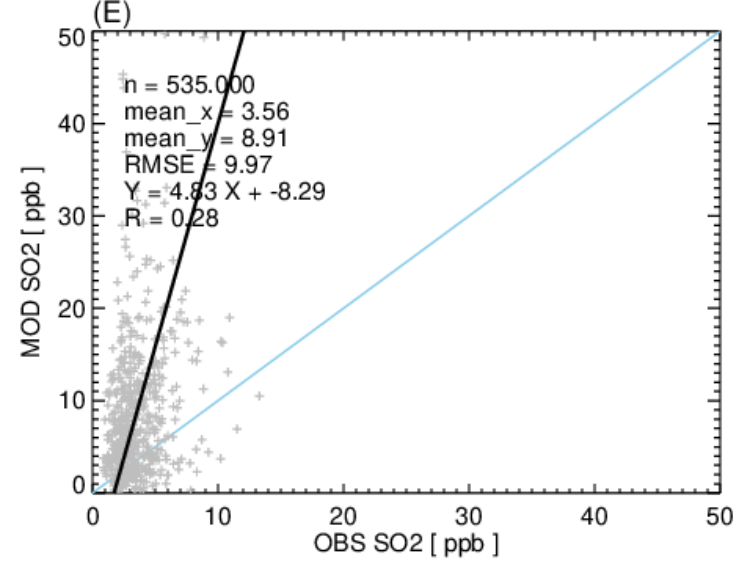

(B)
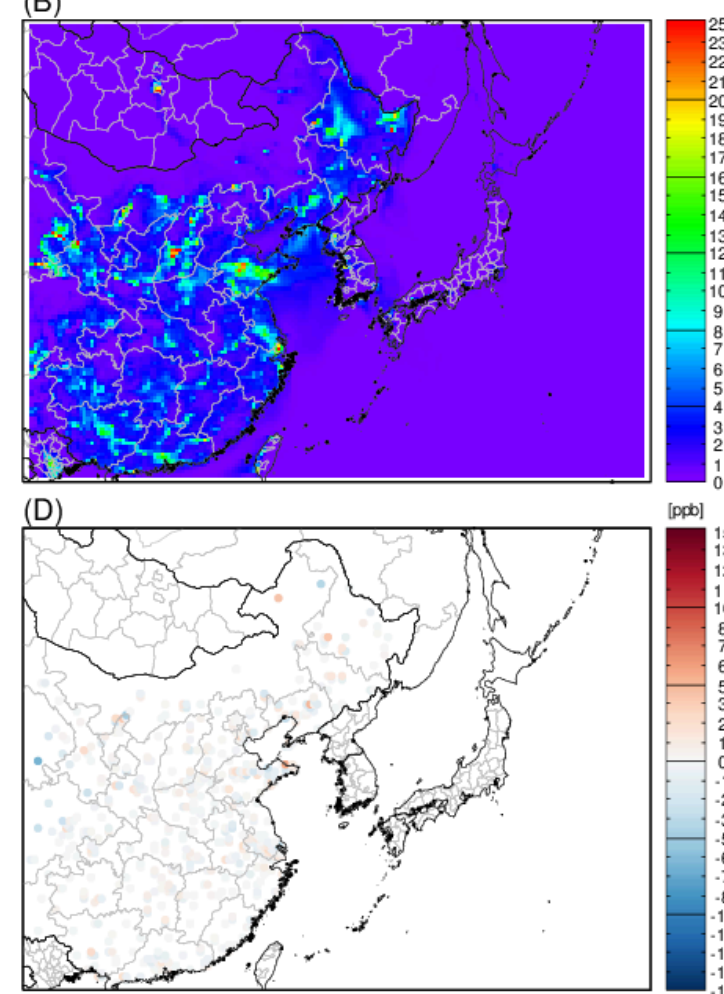

$[p p b]$

[popb]

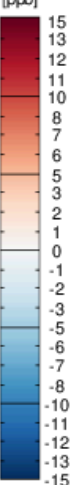

b]

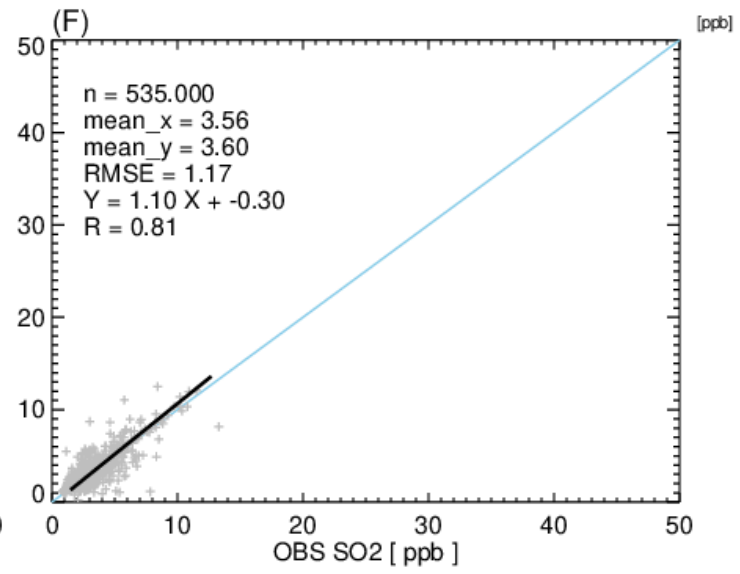

Figure S7 Performance evaluation of models run with initial emissions inventory $(A, C, E)$ and adjusted emissions (B, D, F) for SO2,

Feb-Mar 2020. Shown are spatial distributions of simulated SO2 concentrations (top: A, B) and biases (middle: C, D), as well as scatter plot comparisons for initial (E) and adjusted (F) emissions for February to March 2020. Adjusted simulation is based on the 2-step method outlined in Section 3.2 of the main body of the paper. 
(A)

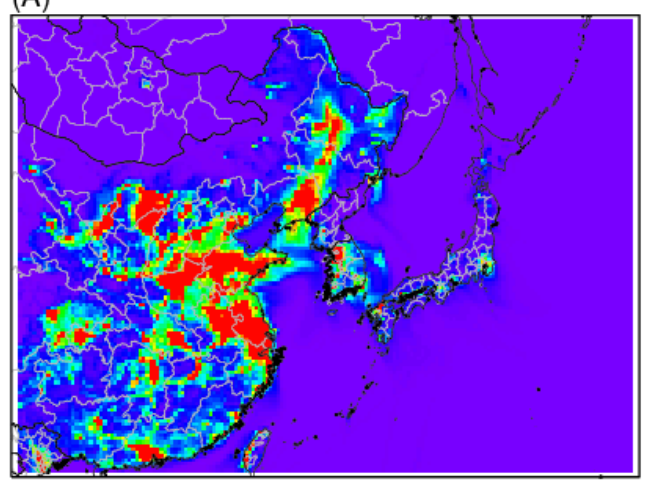

(C)

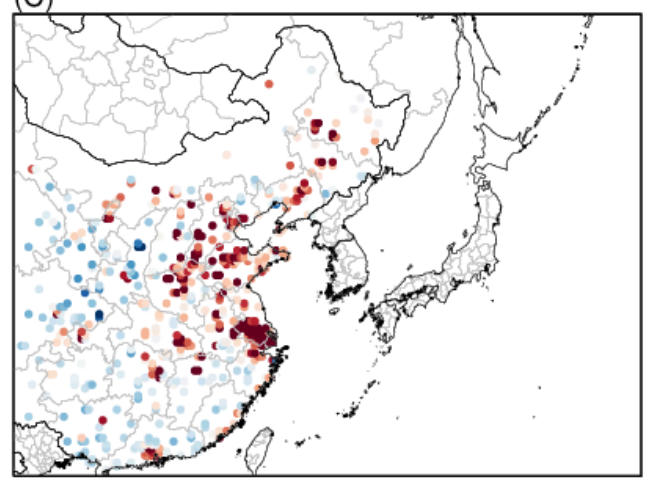
(E)

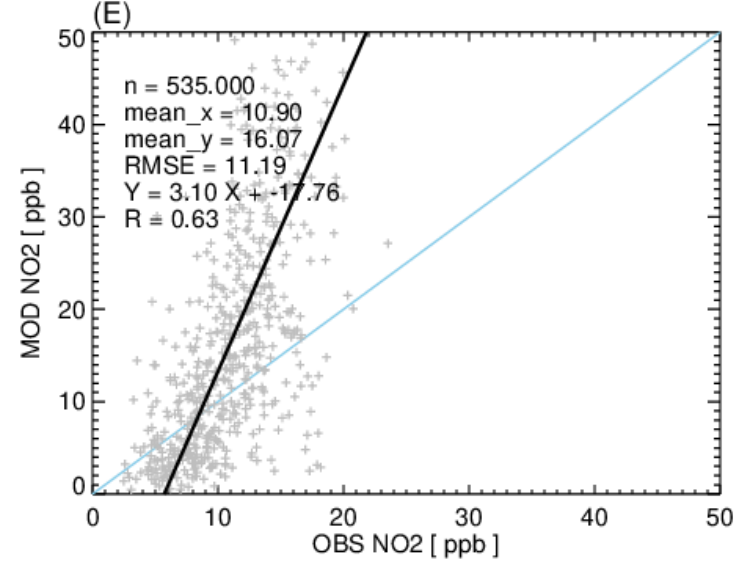

(B)
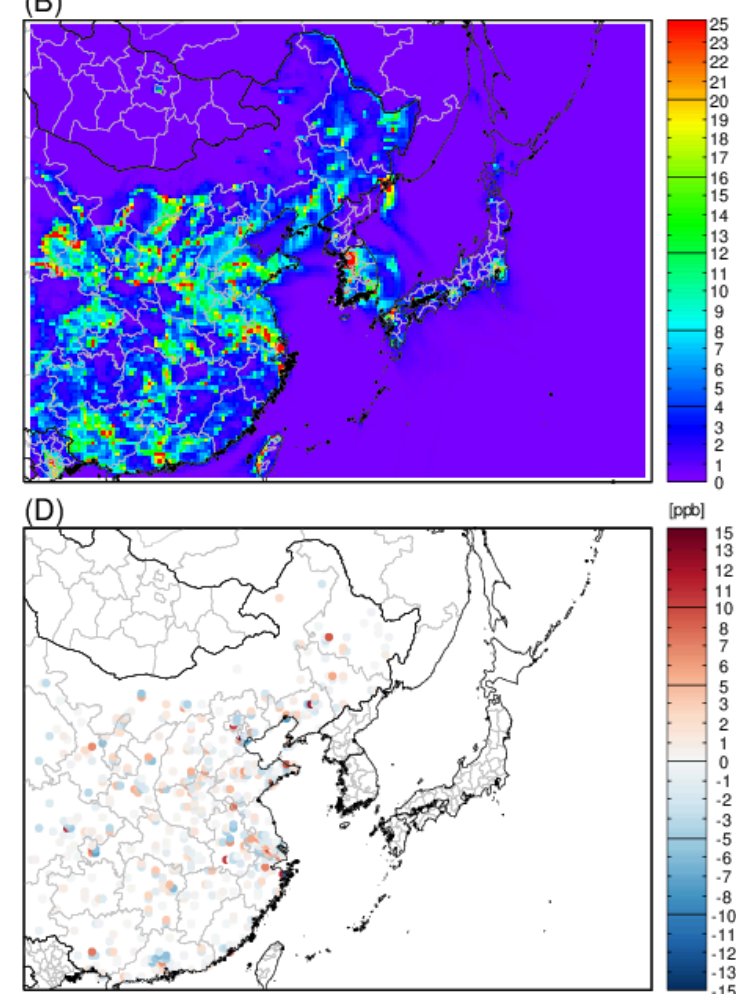

[ppb]

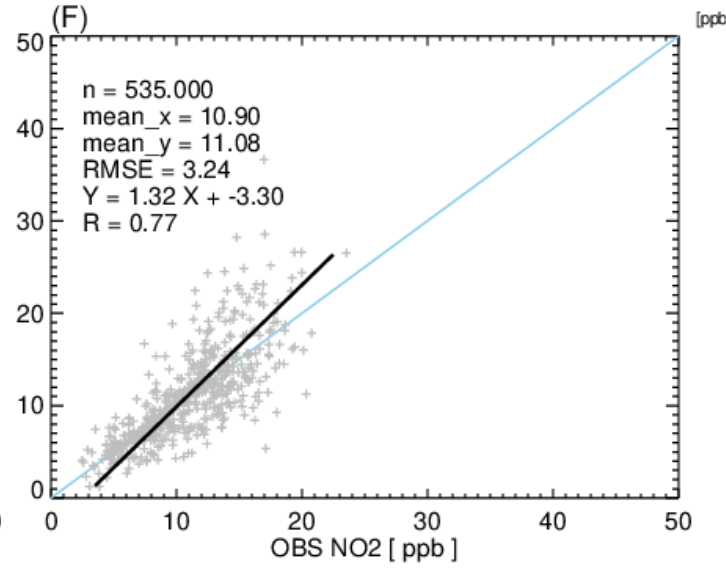

70 Figure S8 Performance evaluation of models run with initial emissions inventory (A,C, E) and adjusted emissions (B, D, F) for NO2, Feb-Mar 2020. Shown are spatial distributions of simulated NO2 concentrations (top: A, B) and biases (middle: C, D), as well as scatter plot comparisons for initial (E) and adjusted (F) emissions for February to March 2020. The adjusted simulation is based on the 2-step method outlined in Section 3.2 of the main body of the paper. 
$\mathrm{PM}_{2.5}$ INITIAL \& ADJUSTED [ Feb-Mar 2020 ]

(A)

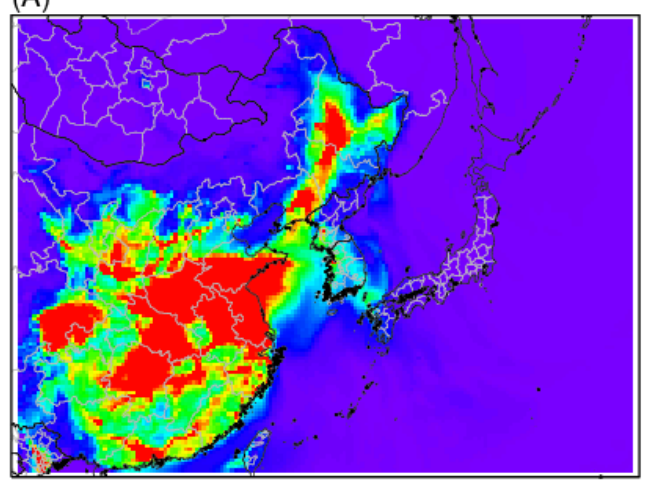

(C)

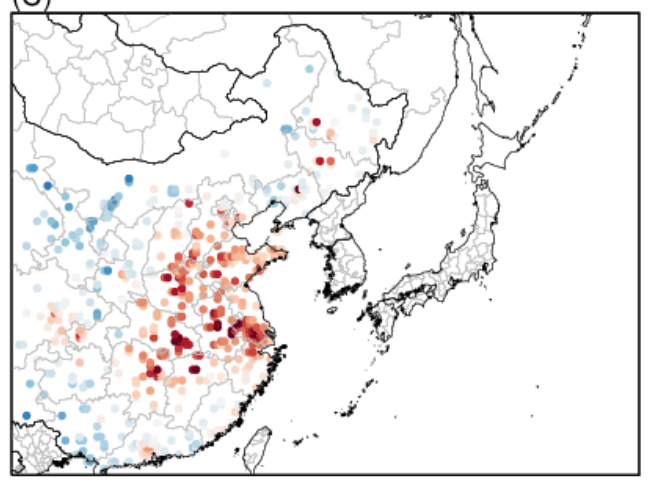
(E)

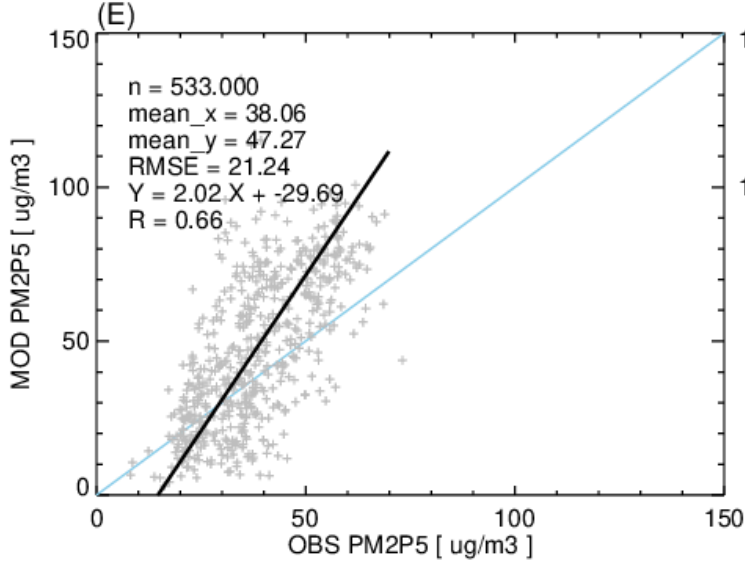

(B)

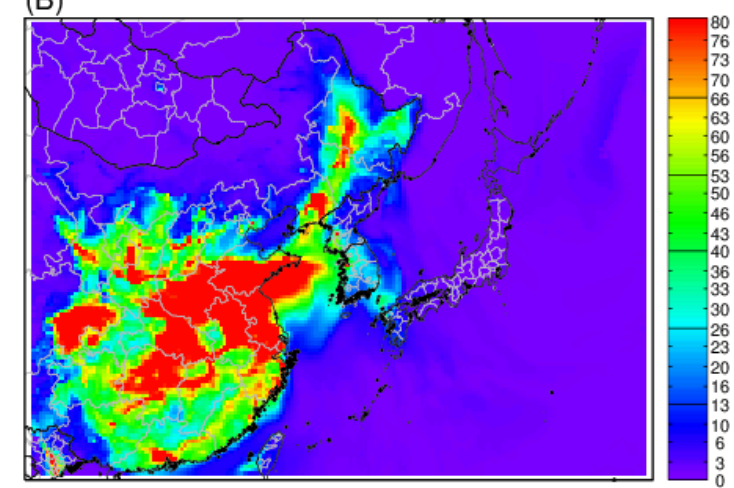

(D)
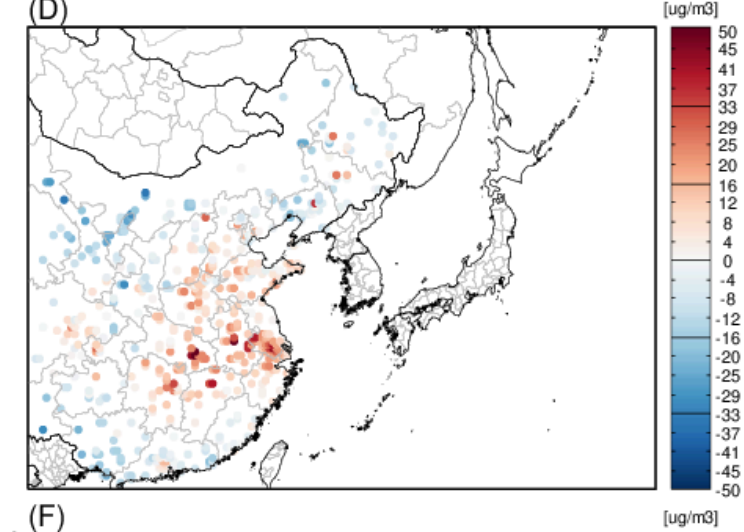

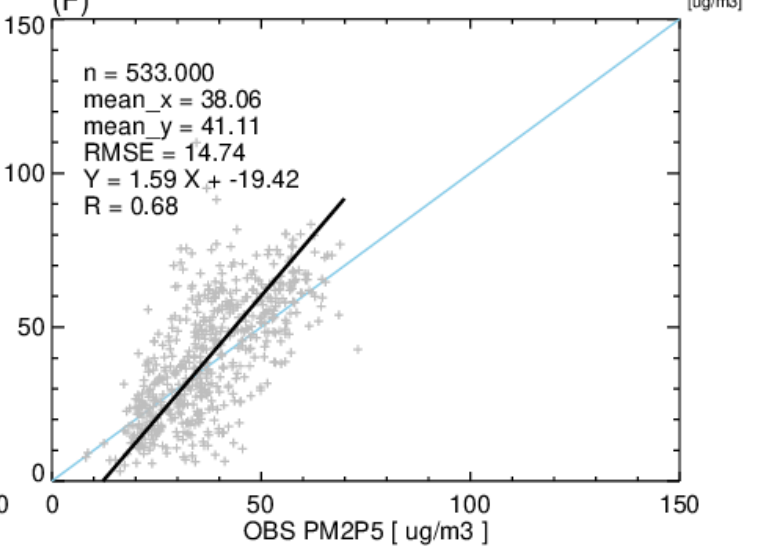

Figure S9 Performance evaluation of models run with initial emissions inventory (A,C, E) and adjusted emissions (B, D, F) for PM2.5, Feb-Mar 2020. Also shown are spatial distributions of simulated PM2.5 concentrations (top: A, B) and biases (middle: C, D), as well as scatter plot comparisons for initial (E) and adjusted (F) emissions for February to March 2020. The adjusted simulation is based on the 2-step method outlined in Section 3.2 of the main body of the paper. 